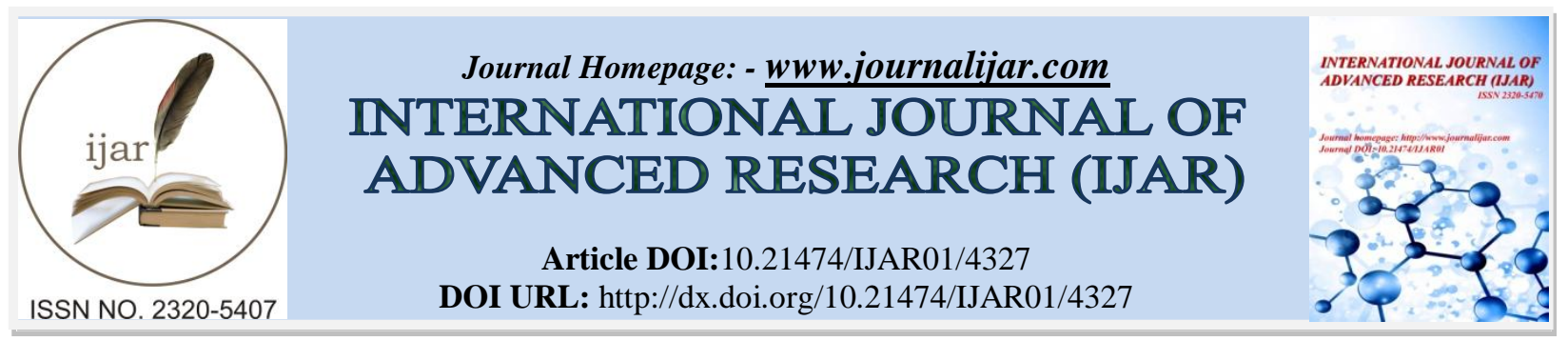

RESEARCH ARTICLE

\title{
NUTRITIONAL STATUS AND DIETARY INTAKE OF MECHANICALLY VENTILATED PATIENTS AT MOI TEACHING AND REFERRAL HOSPITAL-KENYA
}

\author{
Daniel Amdany Komen ${ }^{1,2}$, Silvenus Ochieng Konyole $(\mathrm{PhD})^{1}$,Dorcas Maina ${ }^{3}$ and Dinda Victor ${ }^{1}$ \\ 1. Masinde Muliro University of Science and Technology. \\ 2. Moi Teaching and Referral Hospital. \\ 3. University of Nairobi.
}

\section{Manuscript Info}

Manuscript History

Received: 24 March 2017

Final Accepted: 29 April 2017

Published: May 2017

Key words:-

nutritional status, dietary intake, nutrition therapy practices, mechanically ventilated patients

\section{Abstract}

Critically ill patients are hyper metabolic and have increased nutrient requirements. There is increased catabolism and loss of lean tissue to critical levels after 14 days if patient is starved. The rationale for nutritional support is based upon clinical judgment but the nutritional practices are inconsistently applied for the critically ill patient. The main objective of this study was to determine the nutrition status and compare it to the dietary intake of mechanically ventilated patients. A descriptive cross sectional study design was used to study patients receiving enteral feeds at target or goal rate in 24 hours. Purposive sampling method was used to enroll 39 adult patients who are on mechanical ventilation and feeding enterally. Total daily calorie values were estimated using the institution nutrition data, based on recipes used in preparation of blendrized feeds from the kitchen. Patient's nutrition status was ascertained through laboratory investigation of liver function test showing, direct albumin and protein levels as indicators of catabolic process.mid upper arm circumference was measured to assess the degree of muscle wasting. An energy requirement was determined for the entire sample by using an estimated $25-30 \mathrm{kcal} / \mathrm{kg} /$ day for an average adult weight of $70 \mathrm{~kg}$. A computer statistical package (SPSS) version 22 was used to analyze data. Each patient received $1008.9 \mathrm{kcal} /$ day $(14.4 \mathrm{kcal} / \mathrm{kg} / \mathrm{day})$, protein $1.1 \mathrm{~g} / \mathrm{kg} /$ day, this shows that the patients were underfed. The majority of patients $(67.7 \%)$ were significantly underfed; $25.8 \%$ of patients received less than $50 \%$ of their daily energy requirements. Only 3 patients $(9.7 \%)$ had adequate nutritional intake. There is a relationship between the patient nutrition status \& dietary intake as depicted by .001 . Biochemical data indicated that 11 patients had a mean of 41.31 $\mathrm{g} / \mathrm{dl}$ (albumin) while 23 patients were below the normal range with a mean of $24.9 \mathrm{~g} / \mathrm{dl}$, while 5 patients had direct protein of normal range with a mean of $70.6 \mathrm{~g} / \mathrm{dl}$ while 29 patients were below normal range with a mean of $47.34 \mathrm{~g} / \mathrm{dl}$. From the results on mid upper arm circumference (MUAC) all patients were within the required range with a mean of $29.1 \mathrm{~cm}(23 \mathrm{~cm})$. The study concluded that maintaining optimal nutritional status is key to improving clinical outcome of critically ill patients. 


\section{Introduction:-}

The need for mechanical ventilation in critically ill patients poses a serious risk for underfeeding and progressive malnutrition; this population often receives less than required energy and protein (Kyle et al., 2006; Meara et al., 2008). Administering feeds via the oral route is not an option for the mechanically ventilated patients hence early enteral, or parenteral nutritional support is required to prevent undernourishment. Enteral nutrition (EN) is preferred over parenteral nutrition (PN) because it is more physiologic and less likely to result in hepatobiliary dysfunction and electrolyte imbalance. In comparison to EN, use of PN has been linked to higher incidence of infection, impaired wound healing, and gastrointestinal bleeding (Barr et al., 2004).The most natural and physiological way of obtaining food is via oral intake through the mouth, where food is broken down, transported, digested and absorbed into the body (Tan \& Mathew, 2008). However for the sick, food related behavior change, they may experience loss of appetite, nausea and vomiting, or may not be able to swallow at all, this affect their nutrition intake.

Despite these problems, they still need nutrients to keep alive, to fight infections and to replace lost nutrients. Providing proper nutritional care to critically ill patients has been found to reduce complications, decreasing length of stay and hospital bills (Llano-Diaz et al., 2012). Studies show that early and adequate nutrition are linked to improved tissue healing, decreased physiological stress, and increased immune-competence, which in turn lead to decreased rate of nosocomial infections and pressure ulcers development (Marik \& Zaloga, 2001). Muscle wasting, sepsis, and malnutrition are the leading health care challenges and continue to be the primary causes of mortality within the Intensive Care Unit (ICU). Llano-Diez et al., (2012), cites that ICU patients normally develop relentless muscle weakness and wasting, and subsequently dysfunctional muscle, Preventive approaches like provision of sufficient nutritional feeds, however, have been cited to play significant roles in the prevention of ICU-related complications, such as muscle wasting, sepsis and sometimes deaths (Shefold, \& Weber, 2010). Furthermore, nutrition support has changed from adjunctive care towards an active therapeutic approach with high-quality proof to back the concept that nutrients and nutritional strategies alter the existing morbidity process and influence clinical results, such as health-associated quality of life and post ICU survival.

\section{Nutritional status of patients on mechanical ventilation:-}

Hospitalized patients are at a high nutritional risk. In Brazil, approximately $48 \%$ of the hospitalized patients exhibit some degree of malnutrition. Among these malnourished patients, $12 \%$ are severely malnourished (Waitzberg, Caiaffa, and Correia, 2001) In intensive care units (ICU), the reported prevalence of malnutrition varies between $43 \%$ and $88 \%$. In a recent study, (Heyland et al., 2013) reported that most ICU patients present with sarcopenia prior to admission. In general, illness causes different changes in body function, the metabolic response to injury consists of two phases: the shock phase, characterized by a reduction in metabolic activity, a fall in body temperature, and mobilization of energy reserves (Phelan, 2010; Reid \& Campbell, 2004).

\section{Dietary intake for patients on mechanical ventilation:-}

Accurately assessing nutritional requirements and monitoring the adequacy of nutritional intake in critically ill patients can help ensure that complications associated with underfeeding or overfeeding are avoided. Mathematical estimates of energy requirements are the most common method of determining energy needs in these patients. Traditionally, the Harris-Benedict equation (HBE) has been the accepted standard for determining the energy requirements of critically ill patients. In 1919, Harris and Benedict reported the results of a study done in healthy adult volunteers to determine daily energy expenditure (Ireton-Jones, 2002). The cost of treating a patient with disease-related malnutrition has been estimated at $20 \%$ higher than treating a patient without malnutrition. The Centers for Medicare and Medicaid Services have designated hospital acquired conditions such as catheter-related infections and the presence of stage III or IV pressure ulcers that develop during hospitalization as conditions that do not qualify for payment, leaving hospitals and providers to bear the financial burden. Internationally, the reported prevalence of malnutrition varies from $22 \%$ to $43 \%$ in hospitalized patients. In a follow-up study of intensive care unit (ICU) patients, Kvale et al., (2011) reported that $40 \%$ of patients included in the study lost more than $10 \mathrm{~kg}$ $(22.2 \mathrm{lb})$ of weight during and in the period directly after ICU admission.

\section{Current nutrition therapy practices for mechanically ventilated patients in the unit;-}

According to American Society for Parenteral and Enteral Nutrition, enteral nutrition is liquid nutrition given through a tube and delivered directly into the stomach or small bowel. This liquid nutrition contains protein, 
carbohydrates (sugar), fats, vitamins, and minerals that are needed when a patient is unable to attain an adequate oral intake (ASPEN, 2014). The aim of enteral feedings is to improve or maintain a patient's nutritional status (National Center for Biotechnology Information, U.S. National Library of Medicine, 2006).

\section{Objectives:-}

1. To determine nutritional of patients on mechanical ventilation at MTRH ICU

2. To establish dietary intake for patients on mechanical ventilation at MTRH ICU

\section{Methods and Materials:-}

The study adopted a quantitative cross sectional descriptive survey. This is because the survey research collects information on people's knowledge and opinions. The study was carried out at Moi Teaching and Referral Hospital. The study targeted a population of 63 patients representing three months admission within the period of study and all staffs working in the unit. The sample size was determined using Nassiumas (2000) formula and stratified random sampling a form of probability sampling that were employed to obtain the sampled respondents from the study population. The analysis of the data collected. A self-administered structured questionnaire was given to nurses and other staffs, and a checklist for review of documented interventions relating to enteral nutrition. Descriptive statistics (mean and standard deviation) and inferential statistics (Pearson correlation) were used to analyze data. The ethical approval was obtained from both Masinde Muliro University Moi Teaching and Referral Hospital Research and Ethics committees

\section{Results:-}

Total number of patients included in the study was thirty four (34), 21 were males and 13 were females with mean age of the patient recruited for the study were 43 year. Also 35 staffs were interviewed nine (9) males and twenty six (26) females.

\section{Nutritional status assessment:-}

The study sought to establish the nutritional status of patients at the hospital. The study findings were indicated below

Table 1:- Nutritional status assessment

\begin{tabular}{|l|l|l|l|}
\hline \multicolumn{2}{|l|}{ Biochemical data } & Appropriate range \\
\hline & \multicolumn{2}{|l|}{ Actual results collected } \\
\hline Albumin (g/dl) & Normal range (11) (Mean) & Below normal range (23) (Mean) & \\
\hline & $41.31 \mathrm{~g} / \mathrm{dl}$ & $24.9 \mathrm{~g} / \mathrm{dl}$ & $35-56 \mathrm{~g} / \mathrm{dl}$ \\
\hline Protein & Normal range (5) & Below normal range (29) & \\
\hline & $70.66 \mathrm{~g} / \mathrm{dl}$ & $47.34 \mathrm{~g} / \mathrm{dl}$ & $63-79 \mathrm{~g} / \mathrm{dl}$ \\
\hline MUAC & Normal range (34) (Mean) & Below normal range (0) (Mean) & \\
\hline & $29.13 \mathrm{~cm}$ & 0 & Above $23 \mathrm{~cm}$ \\
\hline
\end{tabular}

Biochemical data in Table 1: Indicates that 11(32.4\%) patients were within the normal range of direct protein level $(41.31 \mathrm{~g} / \mathrm{dl})$ while $23(67.7 \%)$ patients were below the normal range of $24.9 \mathrm{~g} / \mathrm{dl} .5$ patients $(14.7 \%)$ were within normal range with a mean direct protein level of $70.66 \mathrm{~g} / \mathrm{dl}$ while $29(85.3)$ patients were below normal range with a mean of $47.34 \mathrm{~g} / \mathrm{dl}$. Mid upper arm circumference (MUAC) findings showed that all patients were within the required range of $29.13 \mathrm{~cm}$ whereas the appropriate measurement should be above $23 \mathrm{~cm}$

Paired t-tests to determine differences between mean energy required and mean energy received

The researcher took the mean energy required and the mean energy received of 31 patients leaving three patients.

Their results is as shown in the table below

Table 2:- Paired t-tests to determine differences between mean energy required and mean energy received

\begin{tabular}{|l|lcc|}
\hline & Variable & \multicolumn{2}{c|}{ Energy Requirement (kj) } \\
Mean & t & p \\
\hline \multirow{2}{*}{$\begin{array}{l}\text { Estimated requirements } \\
\text { N=31 }\end{array}$} & $89203.6(2877.54)$ & 10.811 & 0.05 \\
\cline { 2 - 4 } & Mean of 1 day intake & $1008.9(2877.54)$ & 0.980 \\
\cline { 2 - 4 } & & & \\
\hline
\end{tabular}


For the total sample of 31 patients, the mean estimated energy requirement of $89203.6 \mathrm{~kJ}$ determined by using the mean daily energy intake. In the 31 patients whose energy requirements were measured, differences between the actual diets recommended 89203.6 and the actual diet taken mean measured $1008.9 \mathrm{kj}$ showed that the patients were underfed

The researcher also sought to test the hypothesis and the results are as shown below

Table 3:- Paired sample correlations.

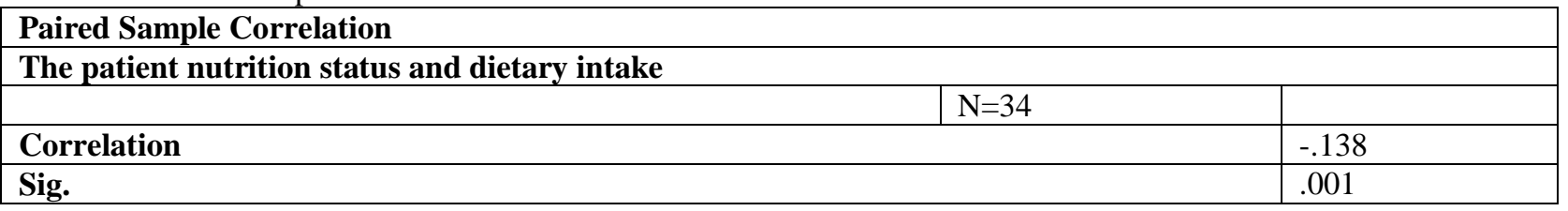

At 5\% level of significance and $95 \%$ level of confidence there is a relationship between the patient nutrition status $\&$ dietary intake as depicted by0.001. Therefore we accept the hypothesis of the study.

Macronutrient requirements versus intakes

The study sought to establish the energy requirement and actual macronutrient intakes of patients. The findings were illustrated in table below.

Table 4:- Macronutrient requirements versus intakes.

\begin{tabular}{|c|c|c|}
\hline Nutrient intake & Appropriate feeding (required) & Actual feeding (n-34)(received) \\
\hline Energy (kcal) & $1869.6 \pm 303.4$ & $1008.6 \mathrm{kcal}$ \\
Energy (kcal/kg per day) & $30.3 \pm 7.4$ & $14.4 \mathrm{~g} / \mathrm{kg} / \mathrm{day}$ \\
Carbohydrate (g/kg/day) & $58.5 \pm 11.1$ & $63.7 \pm 10.45$ \\
& $4.1 \pm 0.5$ & $1.0 \pm 0.3$ \\
\hline
\end{tabular}

\section{Discussion:-}

Nutrition Status:-

By the use of biochemical data to assess patients nutritional status, through albumin and direct protein levels, most patients had below normal range which predisposes patients to high risk of malnutrition, Indicate that $11(32.4 \%)$ patients were within the normal range of $41.31 \mathrm{~g} / \mathrm{dl}$ while $23(67.7 \%)$ patients were below the normal range with a mean of $24.9 \mathrm{~g} / \mathrm{dl} .5(14.7 \%)$ patients were within normal range with a mean direct protein level of $70.66 \mathrm{~g} / \mathrm{dl}$ while 29(85.3) patients were below normal range with a mean of $47.34 \mathrm{~g} / \mathrm{dl}$

\section{Dietary Intake:-}

The ESPEN guidelines for critical care suggest a maximum caloric intake of $20-25 \mathrm{kcal} / \mathrm{kg} / \mathrm{day}$ during the acute and initial phase of critical illness, but $25-30 \mathrm{kcal} / \mathrm{kg} /$ day during the anabolic recovery phase.( Kreymann et al., 2006) cites that certain patients (malnourished or morbidly obese) may have different caloric requirements than the standard patient. This study results has shown that patients received a total of $1008.99 \mathrm{kcal}$ in $24 \mathrm{hours}(14.4 \mathrm{kcal} / \mathrm{kg})$ which is far below the $25-30 \mathrm{kcal} / \mathrm{kg} /$ day predisposing them to severe malnutrition. Overall the present patients had a mean protein intake approximating $1.1 \mathrm{~g} / \mathrm{kg}$ per day, which was inadequate for this critically ill population to achieve a positive nitrogen balance. A negative nitrogen balance indicates protein catabolism and reflects inadequate protein intake. The goal of nutrition support is to achieve a nitrogen balance in the range of $2-4 \mathrm{~g} / \mathrm{day}$. It was therefore not surprising to find that our patients had a negative nitrogen balance throughout the study.

\section{Conclusion and Recommendations:-}

Significantly mechanically ventilated patients received less than required energy and protein, maintaining optimal nutritional status is key to improving clinical outcome of critically ill patients. Knowledge and skills of the healthcare team in nutrition management and the availability of management protocols are important in maintaining optimal nutrition of critically ill patients, increased nursing awareness of nutritional assessment through providing training programs and surveillance of clinical performance is necessary. Management should be concerned with offering an accessible source of knowledge, the required equipment and documentation systems. Enhancing collaboration between health care providers and offering appropriate counseling should also be emphasized. 
The spot check on dietary intake indicated inadequate nutrition due to the nature of preparation of feeds and mode of administration. Improved nutrition saves lives!! There was knowledge gap and lack of clear enteral nutrition guideline/protocol in the unit as demonstrated by staff varied views and practice. There was a significant relationship between the patient nutrition status and dietary intake as shown by low biochemical value; serum Albumin and Protein levels as possible indicators of malnutrition/catabolism; therefore nutrition interventions should form an integral part of critically ill patients on mechanical ventilation care.

\section{Recommendations:-}

The study recommended that;

1. Both kitchens modified and industrially prepared enteral feeds be used to ensure nutrition adequate supply to the patients.

2. There is need to develop an evidence-based enteral nutrition feeding protocol for ventilator dependent patients. A standardized nutrition protocol giving clear instructions on when feeds should be initiated, ryles tube insertion, positioning of patients and when feeding is to be withheld based on gastric residual volume. use of a feeding protocol improves nutrition to ventilated patients and increases patient outcomes

3. Make reading materials available for reference and continuous education programs be initiated to help staff be up to date on enteral nutrition practices.

\section{Reference:-}

1. ASPEN Clinical Guidelines (2014): Parenteral Nutrition Ordering, Order Review, Compounding, Labeling, and Dispensing.

2. Barr, J., Hecht, M., Flavin, K. E., Khorana, A., \& Gould, M. K. (2004). Outcomes in critically ill patients before and after the implementation of an evidence-based nutritional management protocol. Chest, 125, (4) 1446-1457. doi: 10.1378/chest.125.4.1446

3. Heyland DK. (2013)Critical care nutrition support research: lessons learned from recent trials. Curr Opin Clin Nutr Metab Care. 2013;16(2):176-181

4. Ireton-Jones. S, (2006) alteration in nutritional status and diaphragm muscle function. Reprod Nutr Dev. 1998.38(2): 175-80

5. Kreymann KG, Berger MM, Deutz NE, et al., ESPEN Guidelines on Enteral Nutrition: Intensive care. ClinNutr. 2006;25(2):210-23. PMID)

6. Kvale , F., Marshall, (2011) ventilation with continuous positive airway pressure: assessment in normal diet effect with acute respiratory failure. Can ad Anaesth Soc J 27(2):89-95

7. Kyle UG, Genton L, Heidegger CP, Maisonneuve N, Karsegard VL, Huber O(2006)Hospitalized mechanically ventilated patients are at higher risk of enteral underfeeding than non-ventilated patients. Clin Nutr. 2006;25(5):727-35

8. Llano-Diez M, Renaud G, Andersson M, Marrero HG, Cacciani N, Engquist H, (2012). Mechanisms underlying ICU muscle wasting and effects of passive mechanical loading. Crit Care.;16:R209.

9. , P.E, Zaloga, G.P. Early enteral nutrition in acutely ill patients: a systematic review. Crit Care Med 2001, 29 (12) :2264-70. Erratum in: Crit Care Med 2002, 30 (3): 725.

10. Meara D, Mireles-Cabodevila E, Frame F, Hummell AC, Hammel J, Dweik RA, Arroliga AC. Evaluation of delivery of enteral nutrition in critically ill patients receiving mechanical ventilation. Am J Crit Care. 2008;17(1):53-61.

11. Nassiuma D. K. (2000). Survey sampling: Theory and methods. Njoro, Kenya: Egerton University Press.

12. NCBI (2006). Database resources of the National Center for Biotechnology Information. Nucleic Acids Research. doi: 10.1093/nar/gk11031PMCID: PMC1781113

13. Phelan M, (2004) Inspiratory work with and without continuous positive airway pressure in patients with acute respiratory failure. Anesthesiol 63:598-607

14. Reid \& Campbell, (2004) Measurement of static compliance of the total respiratory system in patients with nutrition during mechanical ventilation.. Am Rev Respir Dis 131 :672-677

15. Shefold, \& Weber, (2010) Predictors of prologed mechanical ventilation in a cohort of 3,269 cabg patientes. Minerva Anestesiol. 2007;78(12):615-21.

16. Tan \& Mathew, (2008) Impact of body mass on outcomes following critical care.;123:1202 - 7.

17. Waitzberg DL, Caiaffa WT, Correia MI. Hospital malnutrition: the Brazilian national survey (IBRANUTRI): a study of 4000 patients. Nutrition. 2001;17(7-8):573- 